\title{
PHAC chided for lack of antimicrobial resistance strategy
}

$\mathrm{C}$ anada's Auditor General castigated the Public Health Agency of Canada (PHAC) for failing to lead the way on combatting antimicrobial resistance in one report, and chastised Health Canada in another report for not ensuring that residents of remote First Nations communities have equitable access to medical care.

Canada has recognized the need for a national strategy to reign in imprudent use of antibiotics and to fight antimicrobial resistance since 1997, pointed out Auditor General Michael Ferguson. But PHAC is still "many years" from developing a strategy because it has not built consensus with the provinces, territories and other stakeholders around the strategy's scope, states the report.

"The Public Health Agency has identified that there has to be stronger national leadership," Ferguson said at a news conference. "Well, a lot of that stronger national leadership has to come from the Public Health Agency itself. It has to get those provinces on board."

From 2005 to 2009, the agency gave the Canadian Committee on Antibiotic Resistance $\$ 900000$ to implement a national strategy that the committee had published in 2004. But in 2009, the agency stopped funding the committee.

Since 2009, despite declaring antimicrobial resistance one of the highest public health risks facing Canadians, PHAC has been unable to bring the health and agri-food sectors together or the provinces and territories into the discussion.

One of the key problems, Ferguson said at the news conference, is the ability of farmers to import antibiotics they can use to promote the growth of their animals rather than to fight infections. Health Canada is aware of gaps in reg- ulations that permit that importation but has not closed the loopholes, the report says.

Ferguson wants PHAC to establish "clear and realistic deadlines" for the development of a strategy. Although the auditor general's recommendations are not binding, they have served to move public policy in the past. Health Canada issued a statement following the release of the report.

"We accept the recommendations of this report recognizing that more work needs to be done to build on the considerable progress made to date in addressing antimicrobial resistance," Health Minister Rona Ambrose said in a news release. Health Canada is proposing changes to the Food and Drug Regulations to address the personal importation of veterinary drugs, she added.

Health Canada fared no better in Ferguson's report concerning inadequate training levels for nurses staffing 85 nursing stations on remote First Nations communities in Northern Ontario and Manitoba. Of the 45 nurses whose credentials the auditor sampled, only 1 had completed all five mandatory training courses required by Health Canada.
Since nurses are the first, and often only, line of care in many of these communities, the training courses give them extra competence in advanced cardiac life support, trauma life support, pediatric life support, substance abuse and immunization. The auditor general first flagged the problem in a 2010 report. "We are concerned that this issue persists and that it could negatively affect the health services provided to First Nations individuals," the report says.

Both Health Canada and the Aboriginal Nurses Association of Canada agree that the high turnover and vacancy rates at these nursing stations contribute to the problem. Accessing the courses is also difficult, since not all are available online.

"It's hard for them to get the time and the funding to go," Lisa BourqueBearskin, the nurses association's president, told $C M A J$ in an interview. "You can't leave a community with one nurse to go training for a week. There's already a $40 \%$ vacancy rate."

The report also found that Health Canada did not work with First Nations communities and their community health plans to consider individual needs when allocating resources. For example, some remote communities in Manitoba and Northern Ontario have high rates of suicide, gas-sniffing and other forms of substance abuse that might require particular support and resources. The report also found that Health Canada did not ensure that First Nations residents had access to clinical services comparable to that had by residents in other remote communities. Laura Eggertson, Ottawa, Ont.

CMAJ 2015. DOI:10.1503/cmaj.109-5055 